\title{
Doing sport differently
}

\section{Designing and delivering sport to engage people who are less active}

\section{About this document}

This document is part of a series that aims to help the sporting sector 'do sport differently' to attract, engage and retain Victorians who are less active in sport. It outlines VicHealth's investment in this area and describes six principles designed to support sport organisations to implement new or adapt existing social sport programs.

www.doingsportdifferently.com.au

Related resources include:

$\rightarrow$ A guide for sports clubs

$\rightarrow$ VicHealth program summaries

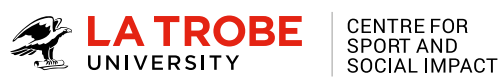




\section{Background}

\section{Nearly half of all Australians are not doing enough physical activity to benefit their health ${ }^{1}$. This contributes to the burden of obesity, chronic disease and mental illness in our community ${ }^{2}$.}

At the same time, trends in physical activity and sport participation are shifting. There is increased participation in social sporting activities and a decline in traditional, club-based sport (Hajkowicz 2013).

Sport organisations are facing the challenge of how best to grow participation in a changing world. People are increasingly time-poor, have varied access to sport facilities, and have limited money to spend on participation. Not everyone wants to join a competitive sport team or is able to meet regular training commitments.

Together, these trends and statistics point to crises in the health of Australians and risks to the viability of our sporting sector. However, they also present new opportunities. Attracting new participants by offering opportunities for social activities increases a sport's reach and sustainability. It also addresses our increasingly sedentary lifestyles and growing rates of obesity.

\section{The way we are being active is changing. Social and recreational activities are increasing, and participation in traditional club-based sport is decreasing.}

\section{CASE STUDY}

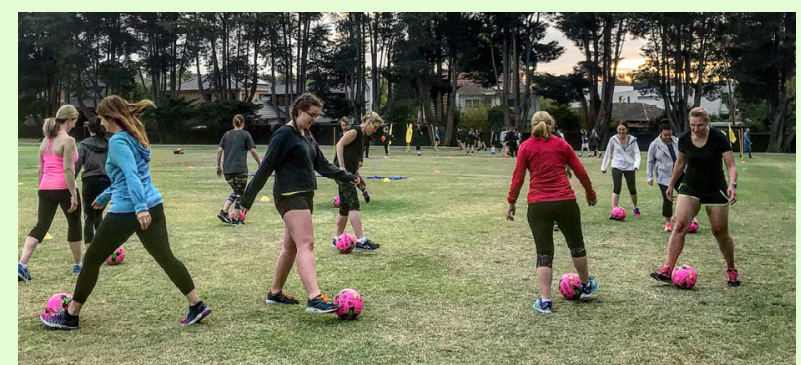

\section{Soccer Mums}

Football Victoria's Soccer Mums program is an introductory soccer program designed specifically to increase the physical activity levels of mothers who are less active.

With no experience required, deliverers can adapt practice sessions for mothers to have fun, meet new people and learn basic football skills. The program is designed to create a welcoming and supportive environment and has been successful in getting women to return week after week. The program's flexible delivery model allows women to miss a week without financial penalty.

Soccer Mums is an important part of Football Victoria's women and girls strategy. Establishing Soccer Mums has taken patience and commitment. Over the past few years, both the content and delivery of the program have seen constant change and will continue to improve and evolve to better meet the needs of Victorian mums. 


\section{WHAT IS 'SOCIAL SPORT'?}

Social sport is less structured than traditional sport. It has fewer rules and more flexibility, but is more structured than active recreation activities. Social sport can be designed and delivered by an organisation (e.g. state sporting association), sport club, local council or other individuals and groups. Social sport places a greater emphasis on fun, social interaction and enjoyment than on performance, results and competition.

Most flexible, least structured

Participate individually or with others
Opportunities for physical activity as part of everyday life
Least flexible, most structured

Participate with others (as individual or as part of a team)

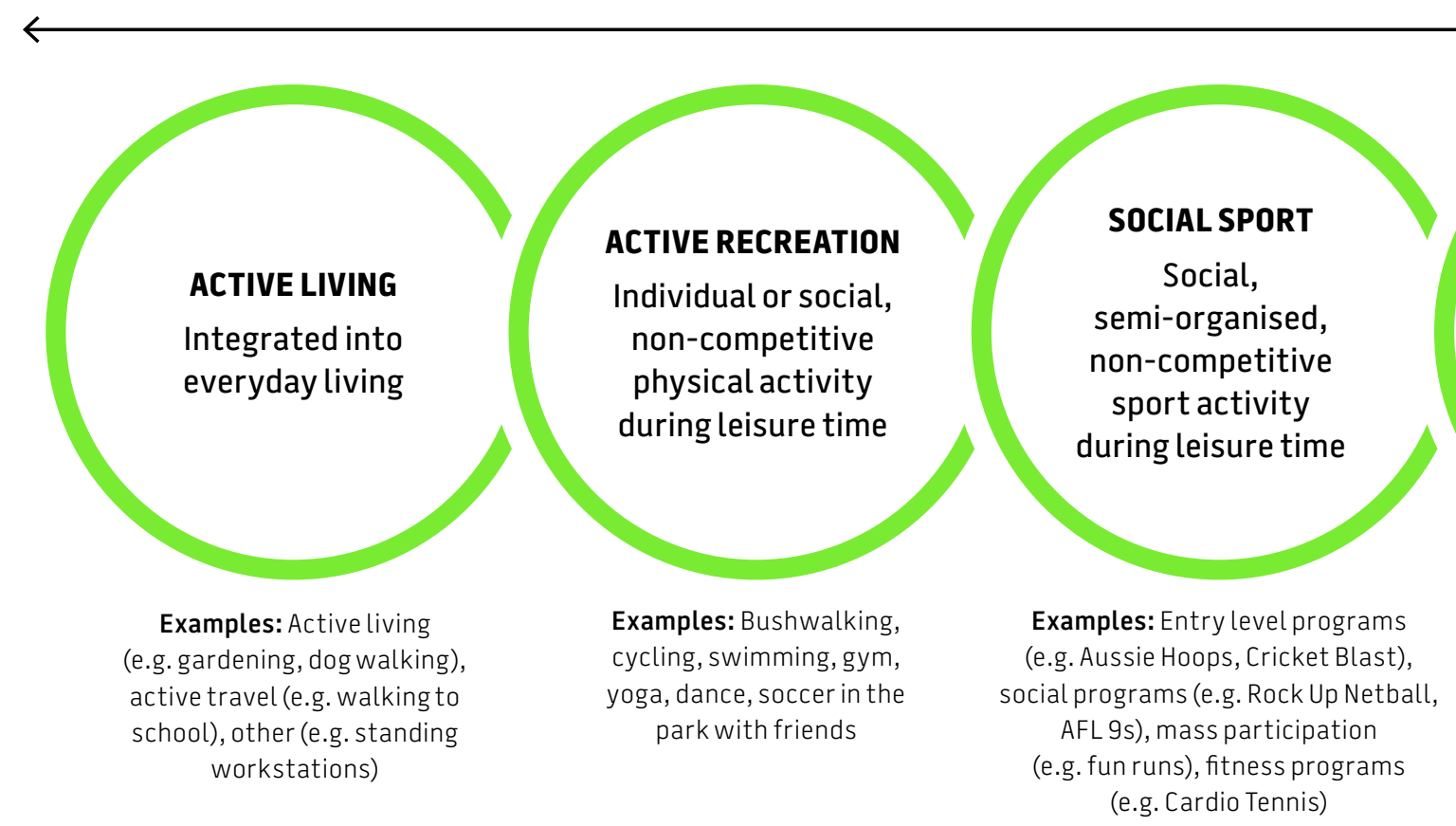

TRADITIONAL SPORT

Local and regional

sports competitions

and events following

traditional rules

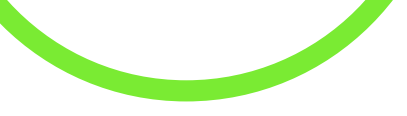

Examples: Tennis competition, local football or netball seasons, cycling event series, Masters Games

\section{ELITE SPORT}

State, national and international sports competitions and events

following traditional

rules where competitors must qualify to participate

\section{Examples:}

Australian Open tennis, AFL, state representation, national championships, Olympic Games 


\section{WHO ARE ‘LESS-ACTIVE’ PEOPLE?}

'Less-active' people are those who don't meet Australian physical activity and sedentary behaviour guidelines, with respect to minutes of cardiovascular activity per week.

People who are less active are those who do not undertake at least 30 minutes of physical activity on at least 5 days of the week. Children who are less active are people under 18 who haven't participated in organised sport (outside school) in the past 3 months.

People might be less active because they have dropped out of sport or decreased their activity levels as their life circumstances changed, or they may never have been active enough.

Some people may not like sport, or might have had bad experiences in the past.

Some people from particular target populations (e.g. from low socioeconomic areas, with disability, culturally and linguistically diverse, Aboriginal and women) may face particular barriers that prevent them from being active. People from these populations may be more likely than the general population to be less active.

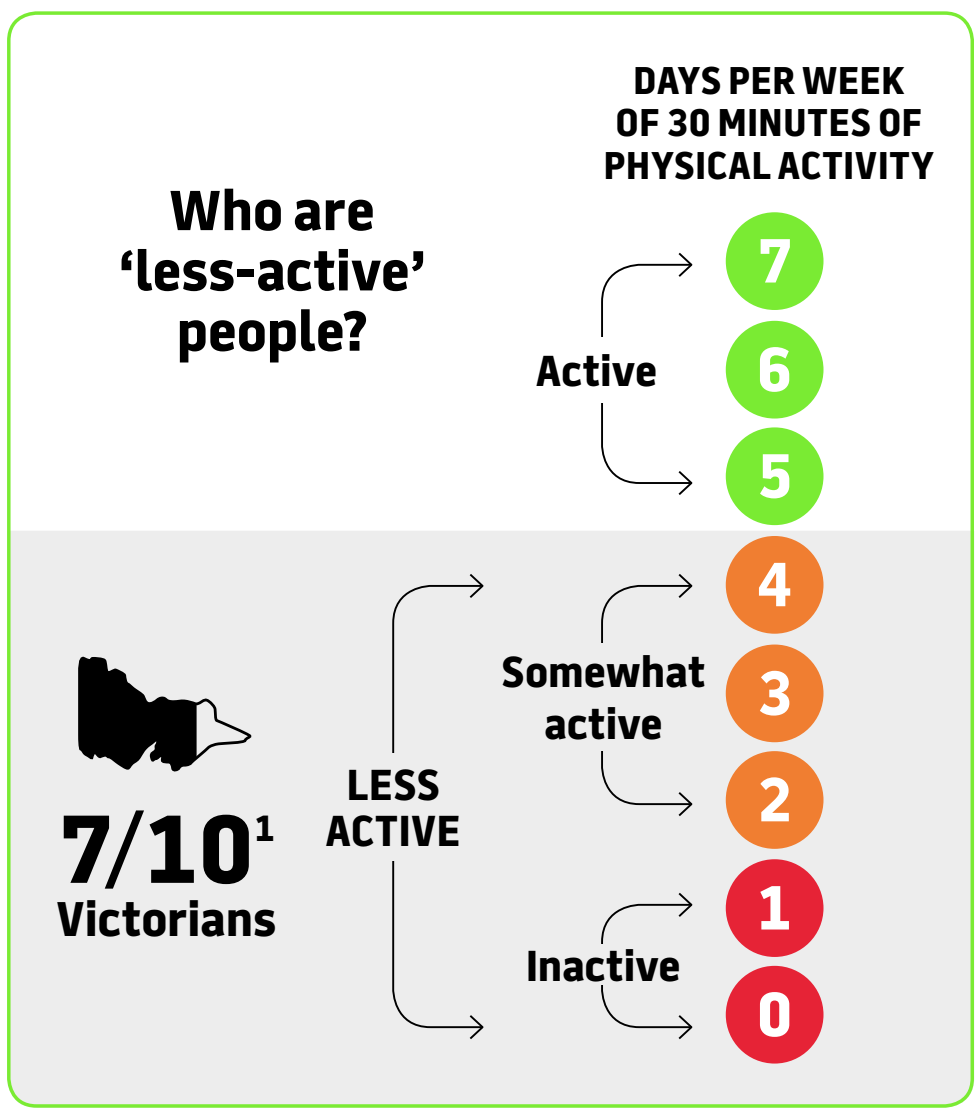

1 ABS 4364055001D0021_20172018 National Health Survey: First Results, 2017-18 - Victoria. 


\section{Background \\ VicHealth's investment}

\section{Between 2015 and 2018, VicHealth has supported Victorians} who are less active to become more active through sport.

VicHealth has invested heavily in a broad range of sport organisations to help them ensure their ongoing viability and engage Victorians who are less active. Many initiatives have assisted local clubs and regional, state and national sport organisations to build more welcoming and flexible approaches to sport participation.

These programs have helped more Victorians become active, keeping them healthy, happy and well.

Approximately $65 \%$
of participants in the
programs supported by
VicHealth were defined as
'less active’ at registration,
compared to $72 \%$ of the
Victorian population.

The new opportunities developed through these initiatives include:

- social sport programs that make activities fun, social and loca

- introductory programs for newcomers to a sport

- programs specifically designed for under-represented groups (e.g. people with disability, newly arrived Victorians, women)

- programs designed to retain participants or cater to people who are returning to sport following a gap.

These programs emphasise fun, social interaction and enjoyment more than performance, results and competition.

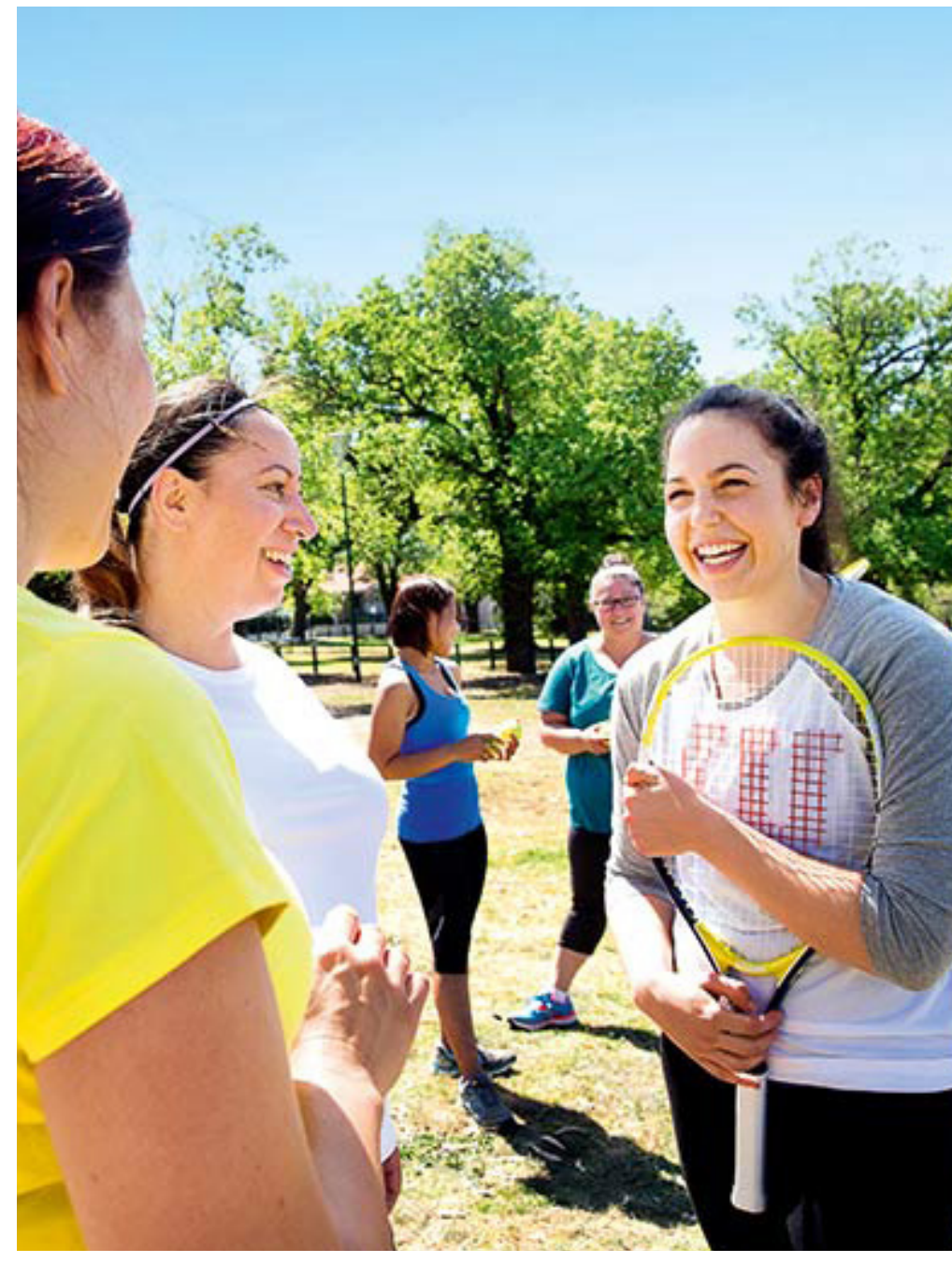




\section{VicHealth's investment in ‘doing sport differently’ (2015-18)}

Female specific

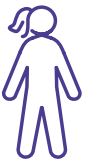

Female Sport Program

Active Women and Girls

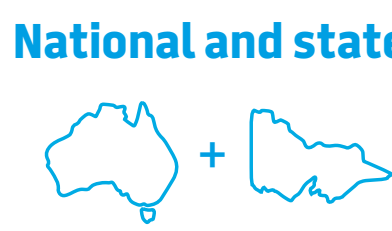

State Sport Program
Regional Victoria

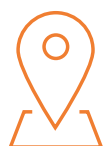

Regional Sport Program
Local

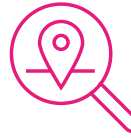

Active Club Grants

Between 2015 and 2018 VicHealth has...

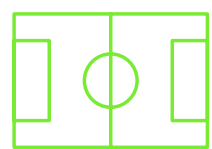

funded $60+$ sporting organisations...

(state sporting associations,

regional sports assemblies and local government)

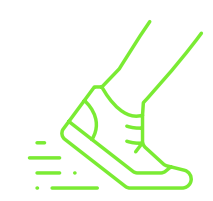

to support 270+ projects...

(developing and delivering tailored sport programs)

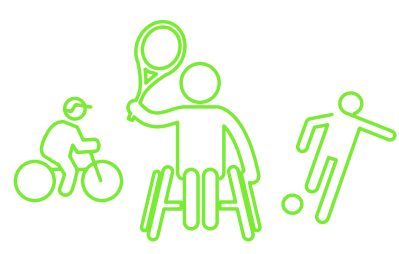

that have

engaged

100,000+

participants..

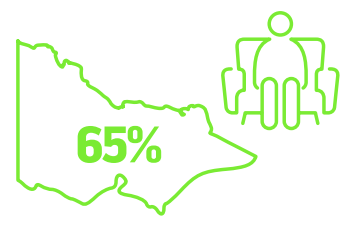

including about

$65 \%$ who were

'less-active'

Victorians...

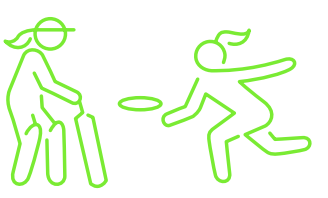

and 16,000+ females

(participating in dedicated programs for women and girls)

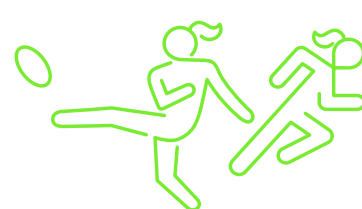

48,000+ people also participated in an initiative of Active Club Grants (including 11,152 females in dedicated programs for women and girls) 


\begin{tabular}{|c|c|c|c|c|c|c|c|c|c|}
\hline Background & $\begin{array}{l}\text { VicHealth's } \\
\text { investment }\end{array}$ & $\begin{array}{l}\text { Benefits for sport } \\
\text { organisations }\end{array}$ & Principles & Principle 1 & Principle 2 & Principle 3 & Principle 4 & Principle 5 & Principle 6 \\
\hline
\end{tabular}

\section{Benefits for sport organisations}

When sport organisations do sport differently, they:

- attract larger and more diverse audiences

- provide opportunities for people at different stages of their lives

- increase the number of participants, volunteers and administrators

- improve their brand

- see their sport thrive into the future

- positively influence the health of Victorians.

Doing sport differently requires rethinking when, where and how sport is delivered, and who delivers it. It may also require new systems, processes and ways of working. It needs patience and a commitment to a new direction.

\section{Doing sport differently can help sport organisations attract larger and more diverse audiences.}

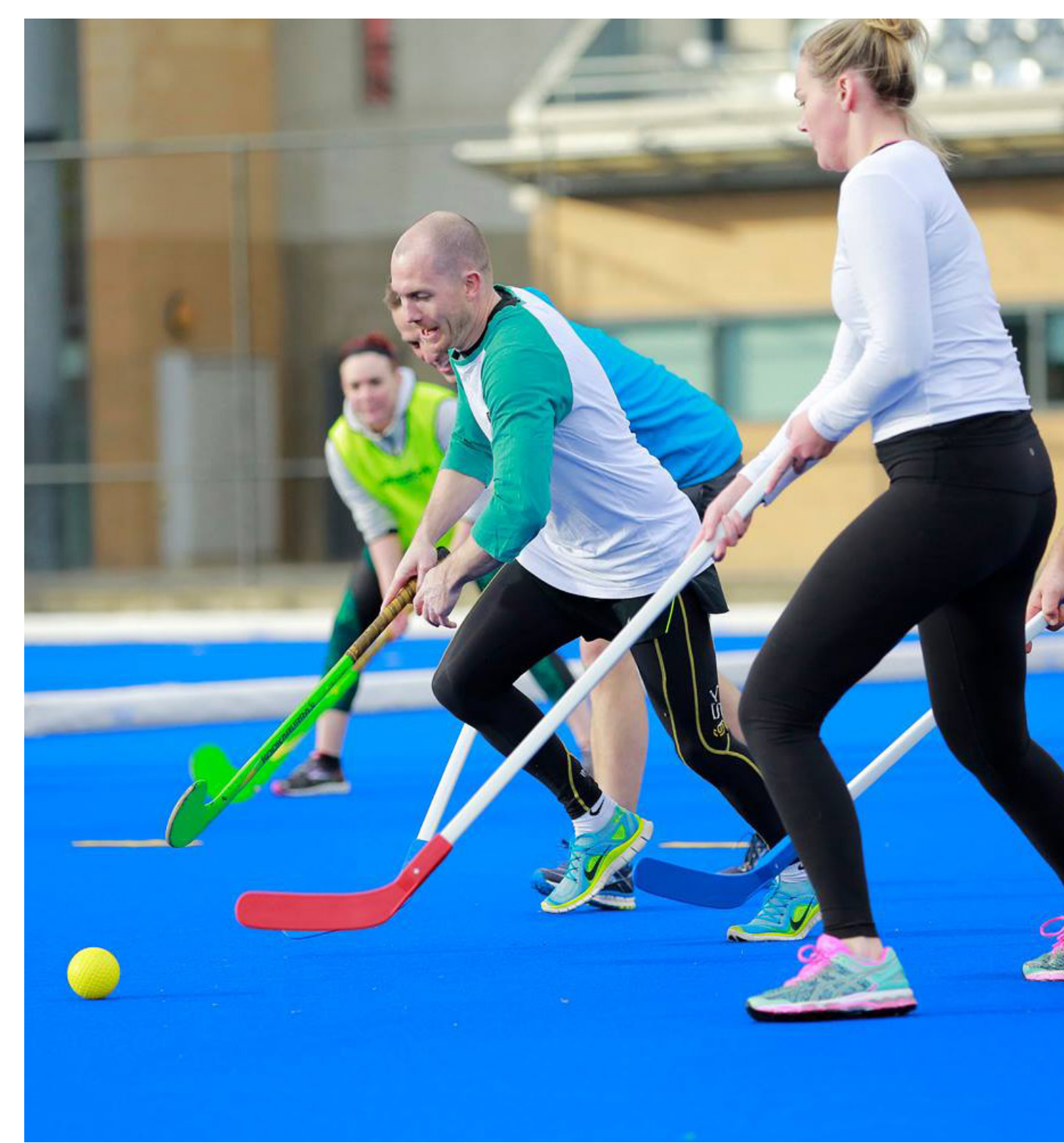




\section{Background \\ Principles}

VicHealth and La Trobe University's Centre for Sport and Social Impact have drawn on years of experience to develop six key principles to guide the design and delivery of sport-based programs that target less-active people.

This document highlights these six principles and provides high-level guidance to build the capacity of the sports sector to create participation opportunities for all Victorians.

The six principles are designed to support organisations through the four phases of implementing a new social sport participation opportunity or adapting an existing one.

\section{Implementing a new social sport opportunity to: engage participants $\mid$ deliver quality programs $\mid$ build a sustainable approach}

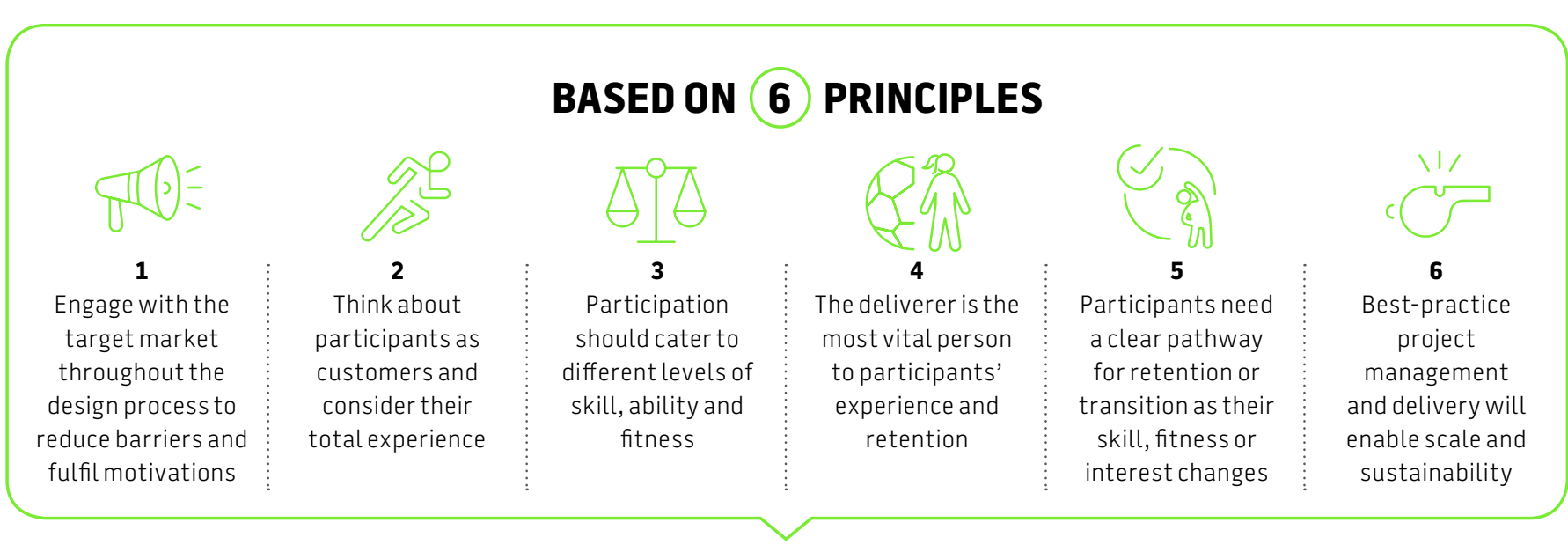

\section{THROUGH 4 PHASES}

1. Design the concept

\section{Develop strategy and resources}

3. Test, refine and roll out the program

4. Deliver at scale 


\section{PRINCIPLE 1: ENGAGE WITH THE TARGET MARKET} THROUGHOUT THE DESIGN PROCESS TO REDUCE BARRIERS AND FULFIL MOTIVATIONS

People who are less active often face barriers to engaging in physical activity that are not shared by 'sporty' or active participants (e.g. a lack of confidence in their abilities or concerns about how they look).

Although people who are less active are all different, they may experience common barriers. Environmental, psychological, social and physical barriers need to be considered and addressed in your design.

The barriers may relate to sport or physical activity in general (e.g. overcoming injury, a lack of options in their local area or a previous negative experience) or to your sport in particular (e.g. not knowing the rules or how to use the equipment, feeling intimidated or not included in the environment).
Try to understand what motivates your customers (current and potential participants) and what participation barriers they face in their daily lives. Talk directly to them to find out what they are looking for in a physical activity experience, especially if they are not attracted to traditional sport.

\section{CASE STUDY}

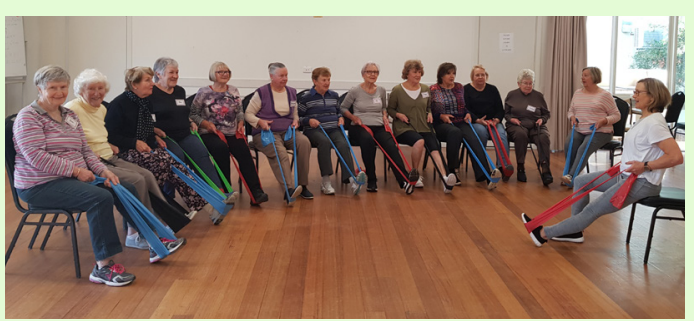

\section{Active Adults}

Leisure Networks' Active Adults program is a great example of a successful co-design process. This multi-site program delivers sport, recreation and leisure activities to older adults in partnership with aged-care facilities and community-based organisations.

Talking to older adults about their preferences helped Leisure Networks design experiences that potential participants were interested in, such as tai chi in the park. This was the key to the program's success.

For the participants, having a social environment in which they could learn new skills and become fitter motivated them to participate more than being involved in competitive sport would have. 


\section{Use innovative program design to overcome barriers}

Innovation helps to attract and engage new audiences by rethinking the who, how, where and when of sport. Innovation does not necessarily mean creating something totally new. Innovative approaches can include developing new or unique partnerships, promoting opportunities in a different way, adapting an existing product to suit a wider audience or improving a process (such as registration) making it easier for people to take part.
Many innovative approaches are highlighted in the

case studies throughout this document. More information and practical examples can be found at www.doingsportdifferently.com.au

Collaborating with traditional and non-traditional partners (e.g. local councils, businesses, community organisations, third-party facilitators) can increase opportunities for innovation and maximise resources and reach.

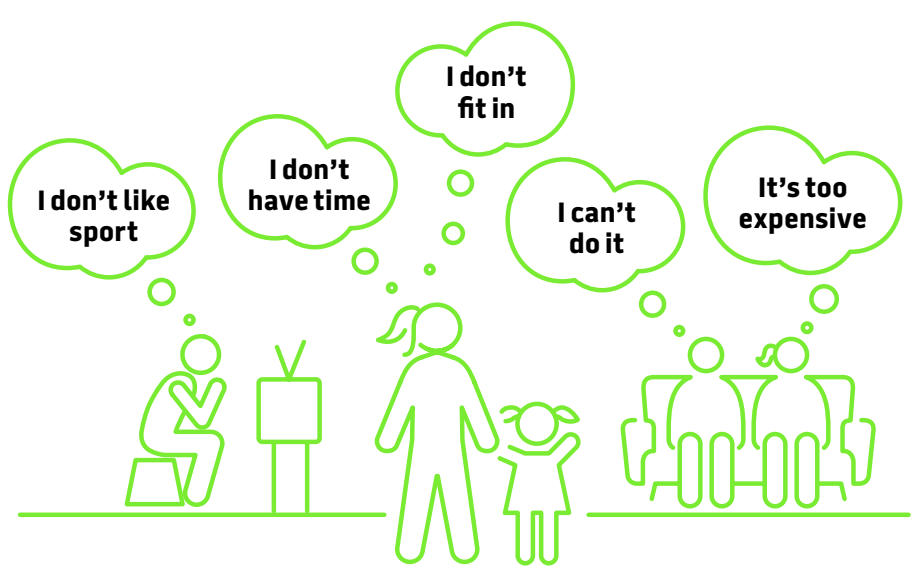

\section{Innovative program design}

\begin{tabular}{|c|c|}
\hline $\begin{array}{c}\text { Flexible payment } \\
\text { options }\end{array}$ & $\begin{array}{c}\text { Modified rules } \\
\text { and equipment }\end{array}$ \\
\hline $\begin{array}{c}\text { Relax the } \\
\text { dress code }\end{array}$ & $\begin{array}{c}\text { More flexible } \\
\text { time slots }\end{array}$ \\
\hline $\begin{array}{c}\text { Online videos } \\
\text { that show the } \\
\text { program }\end{array}$ & $\begin{array}{c}\text { Include social } \\
\text { activities or } \\
\text { other incentives }\end{array}$ \\
\hline
\end{tabular}

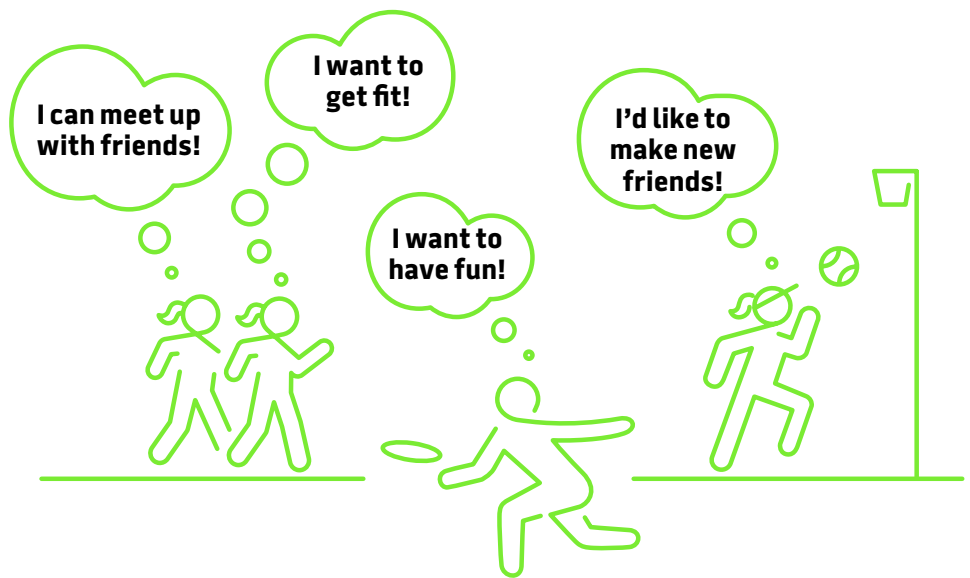




\section{Collaborating with traditional}

\section{and non-traditional partners}

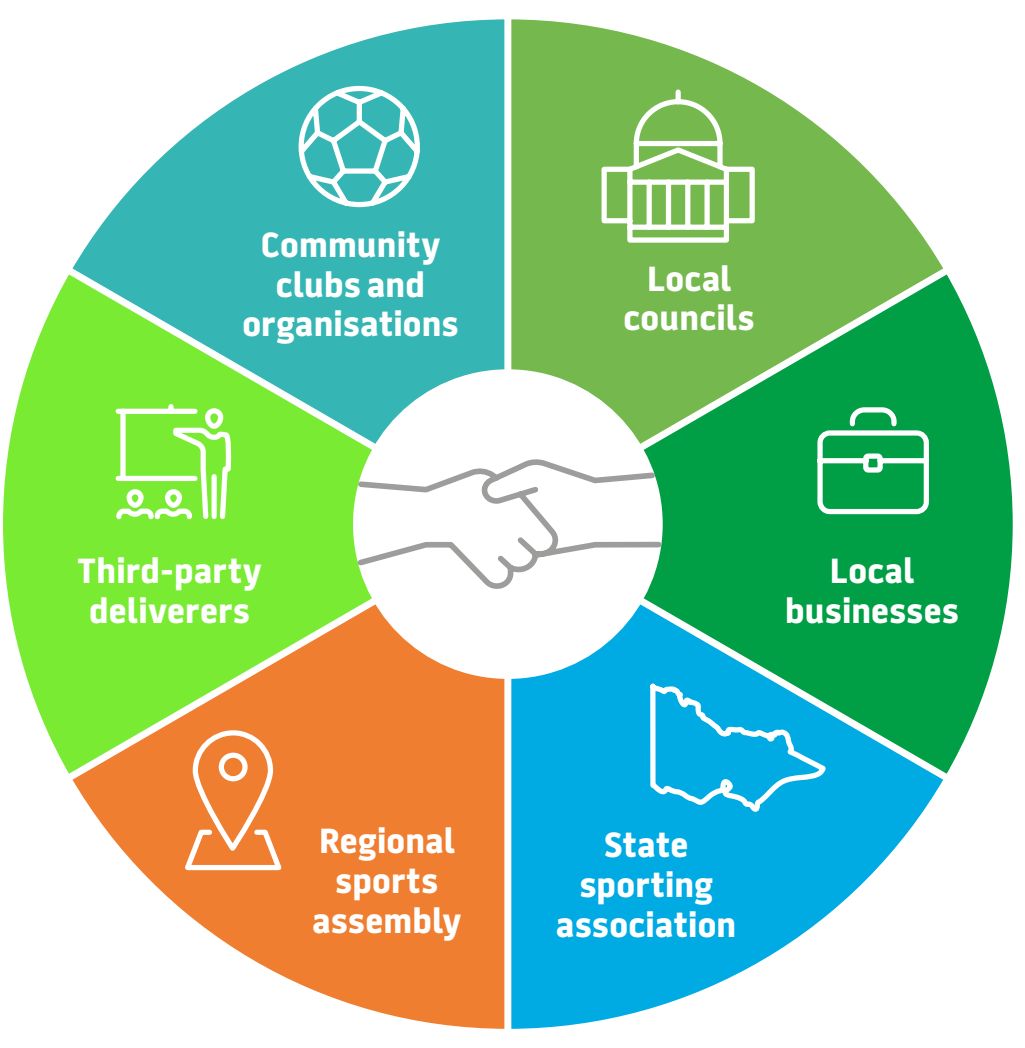

\section{CASE STUDY}

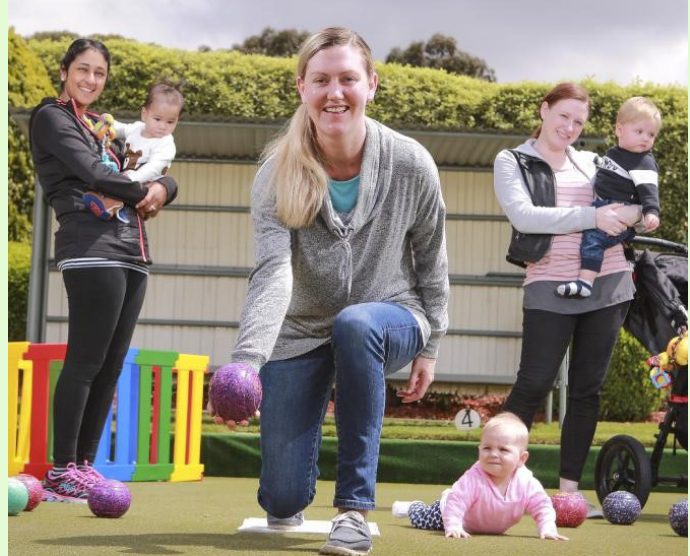

\section{Bowling with Babies}

Bowls Victoria's Bowling with Babies program is an innovative partnership with maternal and child health centres, where nurses recommend the program to new mothers.

This strategy successfully reached the target audience and brought new participants to the sport, contributing to the sustainability of the program. 


\section{PRINCIPLE 2: THINK ABOUT PARTICIPANTS AS CUSTOMERS AND CONSIDER THEIR TOTAL EXPERIENCE}

website feedback form). Think about what systems you will need to gather and analyse this feedback in an efficient way.

We have identified five key touchpoints of the program. These are moments when the participant is likely to decide how they feel about the program and if they are going to continue to participate. As a starting point, concentrate your efforts on improving the customer experience at these key moments.
How will they feel?

What do they want?

What do they need to make them feel comfortable and welcome?

The customer engagement process is more effective if it is ongoing and includes regular feedback loops from varied sources (e.g. surveys, face-to-face interviews,

\section{Five key customer experience touchpoints}

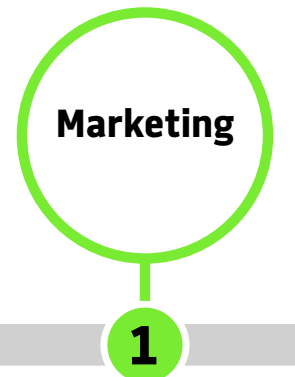

Help less-active people 'see'

themselves doing the activity

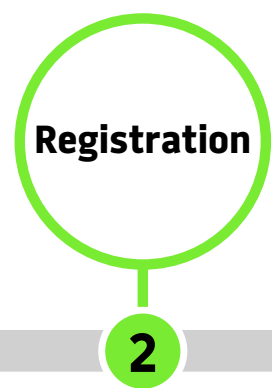

Make it easy to get involved and ensure participants understand what

to expect and what to do

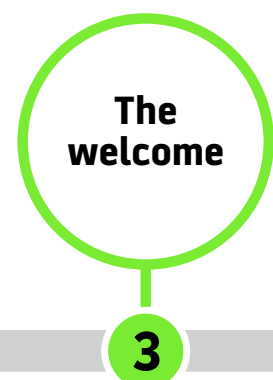

Greet participants and introduce them to each other to support group cohesion

Balance volume of information to overcome fear of the unknown but avoid overload

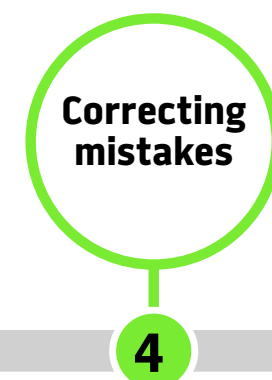

Train the facilitator o correct mistakes appropriately, manage other participants' reactions and be supportive in these crucial moments

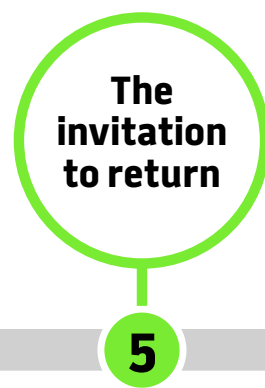

Touch base with each participant at the end of each session to increase retention (and potentially follow up via text or email) 


\section{Marketing}

The first customer touchpoint is marketing. This is a vital engagement opportunity. A program-wide marketing campaign supported by local marketing strategies is a good way to attract less-active people to participate.

Less-active people often contemplate joining an activity for a while before they follow through. Think about how you can help potential customers feel that the activity is achievable for them, and that the group will be supportive and made up of people like them (in terms of skill and motivation). Aim to make the registration process as simple as possible.

Make your marketing content
relevant to less-active
participants. It is important to
think about how your marketing
strategies can reach beyond people
who are already engaged in the
sport and attract new customers.

\section{CASE STUDIES}

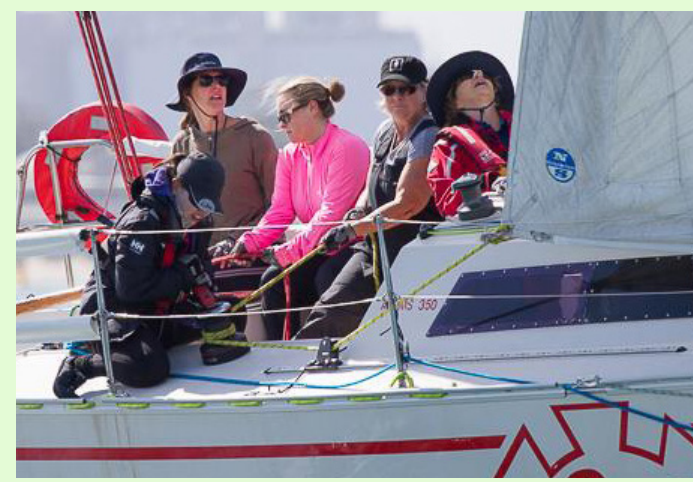

\section{Get Active Sailing}

Get Active Sailing, run by Australian Sailing, successfully used word-of-mouth to promote entry-level sailing programs to family, friends and colleagues of existing members.

This strategy specifically addressed common misconceptions by promoting the fact that participants didn't need to own a boat or have any sailing experience to take part.

As participants already knew someone in the club, their first experience of sailing was friendly and comfortable.

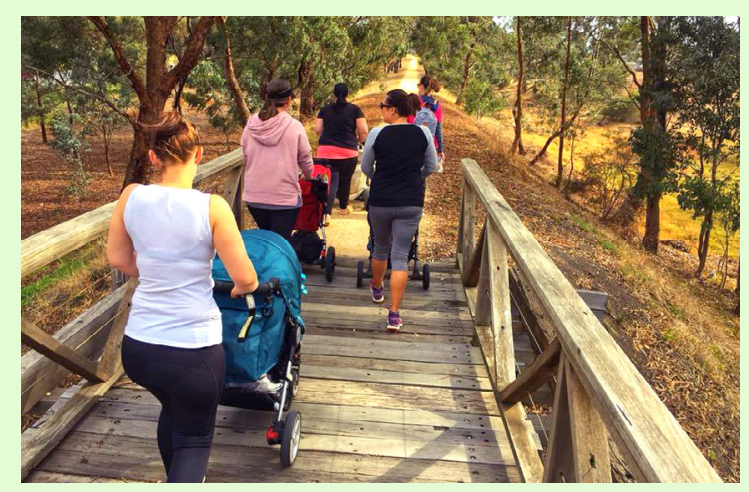

\section{Miss Me-time}

For many women, walking into a sport club can be daunting, especially if they are stepping into sport for the first time, or returning after a long absence. The Miss Me-time initiative, developed by Sports Focus (the Regional Sports Assembly for Loddon Campaspe region), supports women in Bendigo to take part in fun, affordable physical activity options in friendly, flexible and supportive environments. It tackles the participation barriers felt by women by creating places where they can have fun while being supported and encouraged.

New participants are greeted by an empathetic, relatable, non-judgemental, warm and friendly welcoming officer. This ensures that the customer's first participation experience is a positive one, which encourages them to come back. 


\section{PRINCIPLE 3: PARTICIPATION SHOULD CATER TO DIFFERENT LEVELS OF SKILL, ABILITY AND FITNESS}

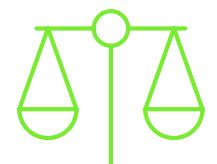

When an activity cannot be successfully completed, or is not challenging enough, participants are more likely to disengage with a program. When activities are flexible and can be modified and adapted for all members of the group, participants are more engaged and their confidence and ability increases.

Think about how your activities might be adapted to engage and retain participants. This could be done through:

- using different equipment

- having different movements to increase or decrease the challenge

- splitting participants into groups according to skill, ability and fitness levels

- changing the rules, playing area, duration of games or scoring to suit everyone's skill level and ability.
It is also important to consider the difference between 'beginner' and 're-entry' participants. Adult beginner programs need to include very basic activities to build participants' confidence and skills. Re-entry participants will probably already have some

knowledge or skill memory, so they are likely to improve at a faster rate.

Injury prevention is also important, especially when participants are new to the sport or haven't exercised for a while.

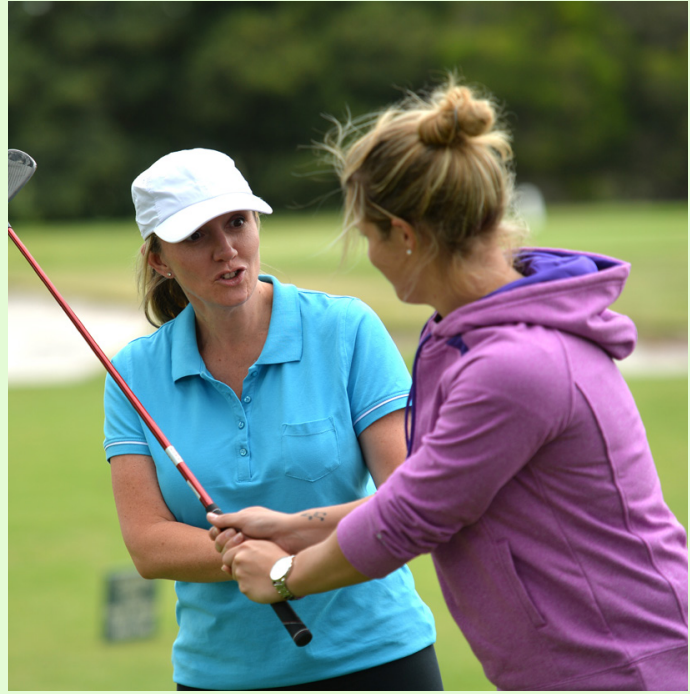

\section{Swing Fit}

In Golf Australia's Swing Fit program, golf and fitness activities were designed to be done in pairs, so that beginners and re-entry participants could be matched. Alternatively, if a re-entry and beginner were paired, the facilitator could motivate the re-entry participant to be a role model or mentor for the beginner.

Managed well, this approach can motivate and challenge all participants and build positive relationships. 


\section{PRINCIPLE 4: THE DELIVERER IS THE MOST VITAL PERSON TO PARTICIPANTS’ EXPERIENCE AND RETENTION}

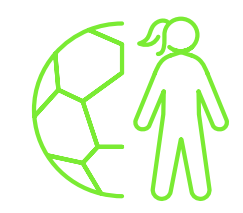

The deliverer - the person facilitating the activity - is responsible for welcoming, engaging and encouraging participants.

Traditional coaching methods that are based on skill acquisition and development may not be the best way to engage and retain less-active participants. Focus on recruiting and training deliverers based on their ability to be empathetic and engage with participants, rather than their coaching ability alone.

Whether they are paid staff or volunteers, adequately train deliverers to understand the audience, the aims of

The best deliverer for people who are less active may not necessarily be a traditional coach.

\section{Deliverer}

NEEDS TO BE

empathetic

encouraging

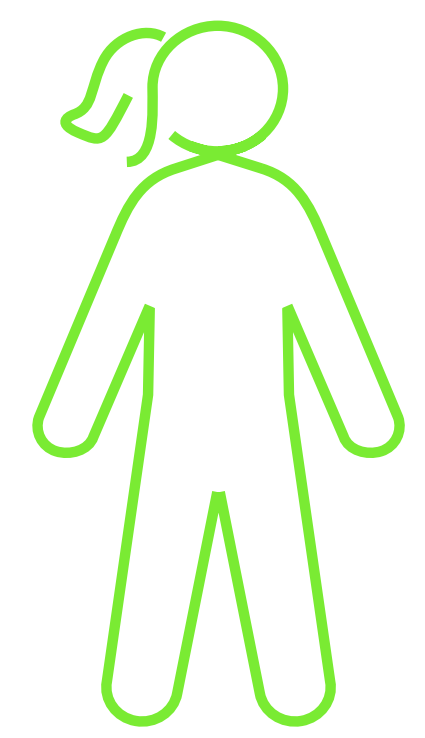

ABLE TO

control group atmosphere and social cohesion

provide clear instructions

modify activities 


\section{CASE STUDIES}

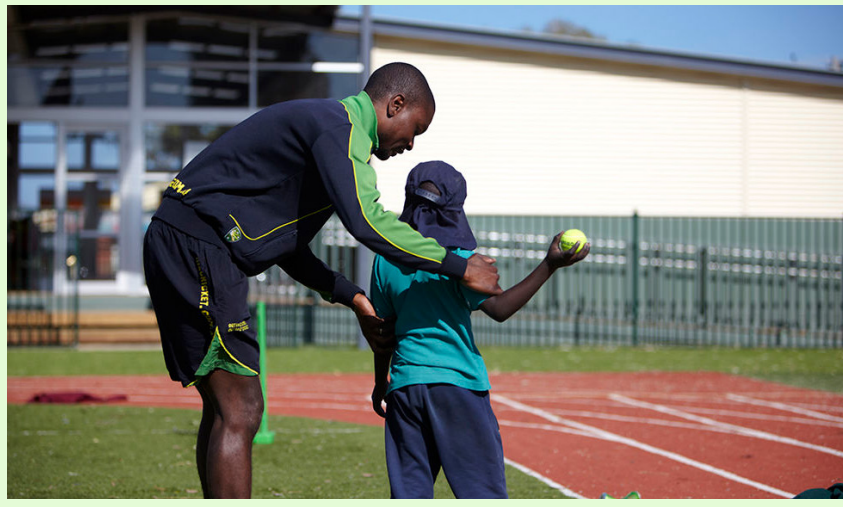

\section{Cricket Victoria}

Cricket Victoria developed a set of stand-alone cricket programs for culturally and linguistically diverse

participants (some of whom were new arrivals to Victoria) in partnership with specific community groups (e.g. Nepalese Cricket Association)

It was essential that deliverers were trained in how to work with these participants. The deliverers had to understand that while some participants may be very experienced with cricket, this would be their first experience with the Australian community sport system. For other participants, it may their first experience learning any sport at all.

The deliverers also needed to appreciate that participants may be facing significant challenges outside of the program, such as learning English, navigating a new community, financial hardship or lack of transport.

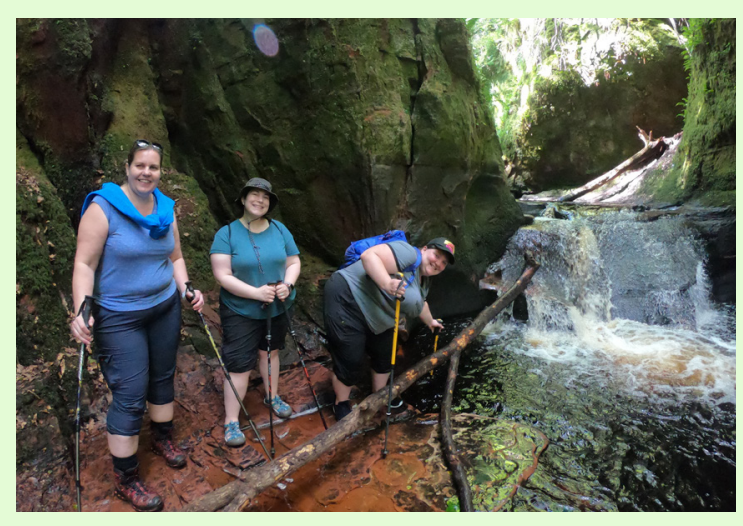

\section{Escaping Your Comfort Zone}

Escaping Your Comfort Zone is a bushwalking program for plus-sized women that has created an environment where women feel they belong and are empowered to participate. The walks are designed for beginners and run by volunteer leaders.

The success of this program hinges on leaders who understand the fears of women who may not be confident in their body and their ability to exercise.

\section{Leaders are trained in making sure everyone is} comfortable and that no one is left behind. They do this by walking at the pace of the slowest person and allowing the women to build up their distance over time. 


\section{PRINCIPLE 5: PARTICIPANTS NEED A CLEAR PATHWAY FOR RETENTION OR TRANSITION AS THEIR SKILL, FITNESS OR INTEREST CHANGES}

One of the aims of social sport is increasing participants' regular physical activity levels in order to achieve health benefits. For sport organisations, retaining participants is also important for their ongoing viability. It is useful to consider 'What's next?' for participants, particularly those who have participated in short-term opportunities (e.g. a 4-6-week introductory program).

What participants want to do next will vary. Some will increase their skill and fitness levels through the program and then seek more challenging opportunities. For others, their interest and skill may decrease (e.g. as they age), meaning that a different offering will be more attractive. Some participants want variety in their activities and others prefer to stick with the sport they have come to know, at an appropriate level.

All these pathways should be considered as part of your program design.
Outside your sport, other options may be brokered or promoted by partners like your local council or a regional sports assembly that has networks across a range of sports.

Remember that successful transitions are often dependent on the quality and knowledge of the delivere and how well they encourage continuation and link to new opportunities.

\section{Consider the existing pathways} within your own sport and keep in mind that transition to annual membership or a competitive version of the sport should not be the only option. This is generally not what people who are less active are looking for.
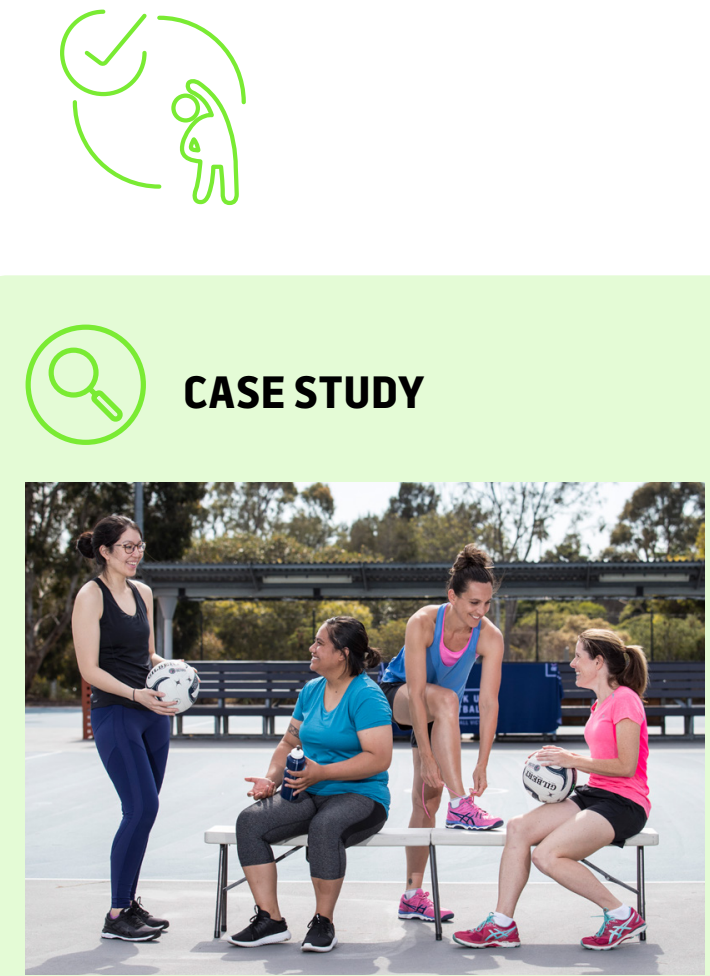

Rock Up Netball

Netball Victoria’s Rock Up Netball social sport program has a built-in progression pathway for participants using 'train and play' elements. The 'train' element allows participants to build and practice netball skills in a supportive environment.

Once participants feel confident, they can play in festivals or social competitions, allowing them to experience the game in a fun, non-competitive environment. 


\section{What's next for the participant?}

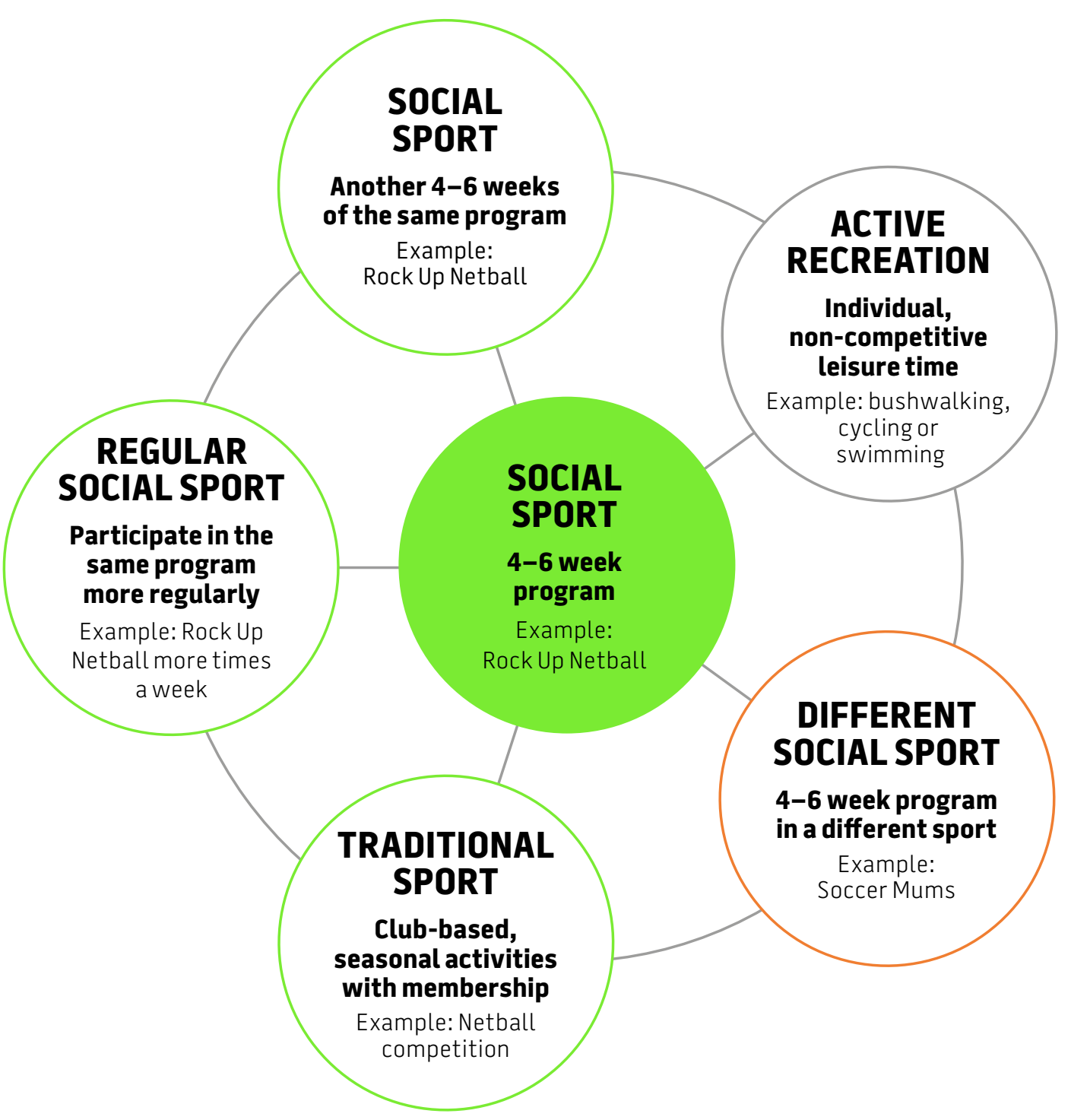

\section{CASE STUDY}

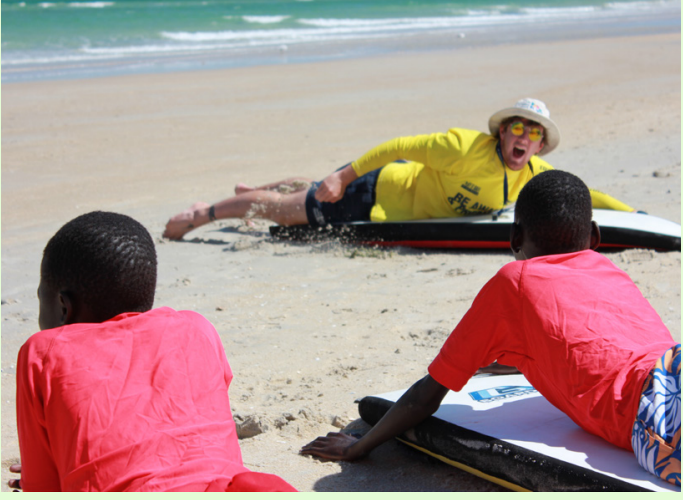

\section{Life Saving Victoria}

Life Saving Victoria supports culturally and linguistically diverse participants to advance through a series of program activities designed to help them and their families be physically active in water. These activities progress from a free beach-based program focused on water safety (delivered by Life Saving Victoria) to swimming programs (delivered by private facilities) in which the whole family is given an opportunity to swim.

This transition strategy involving multiple programs, facilities and partners has taken time to develop. It exemplifies the level of consideration needed to deliver successful outcomes for diverse communities. 


\section{PRINCIPLE 6" BEST-PRACTICE PROJECT MANAGEMENT AND DELIVERY WILL ENABLE SCALE AND SUSTAINABILITY}

Some target audiences may be small, which limits opportunities to up-scale programs. However sustainability at a small scale can be achieved. Some populations may have a reduced ability to pay, and some programs cost more to deliver than others.

Despite these challenges, sustainability remains a vital component of any program design. Planning for a program's ongoing viability means that the benefits of doing sport differently - for both the sport and lessactive people - are maintained in the longer term.
A good learning for us was to be ready for funding opportunities by having some scoping and critical thinking done prior. I call it the third drawer project . a good idea waiting for investment. Your idea should involve minimal costs and minimal technical build to ensure you can get it to the marketplace quickly and start learning. Succeeding or failing fast gives you the platform to accelerate or change direction before significant investment (time or money).

\section{Grant Cosgriff}

Executive Director, Triathlon Victoria

\section{CASE STUDY}

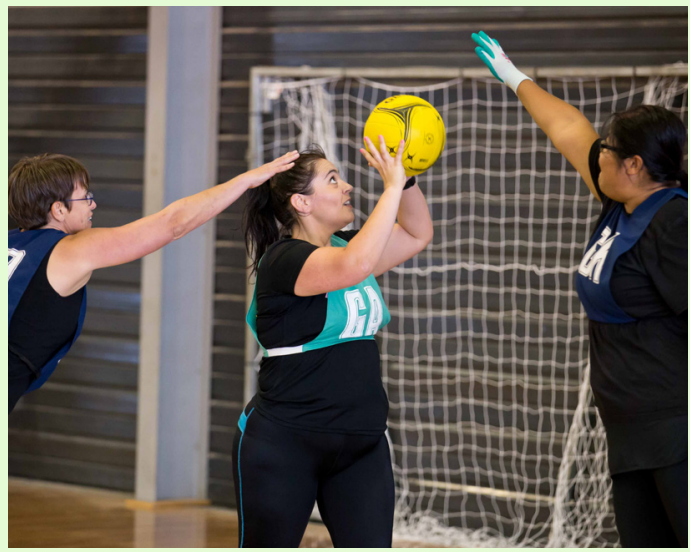

Netball Victoria

Netball Victoria created an online registration platform and website that allowed them to license the Rock Up Netball program. When licensees use the online platform for promotion, registrations and fixturing, revenue is returned to the sport. This provides greater opportunities to expand the Rock Up Netball brand across Victoria and increases the sustainability of the product. 
Sustainability should be considered - and can be achieved - at both the local delivery level (e.g. club) and the program level. VicHealth and La Trobe University's Centre for Sport and Social Impact have identified some key characteristics of sustainable sports programs that target less-active people. In planning for sustainability, consider each of the factors identified at each level, and build momentum by demonstrating success and value early.

\begin{tabular}{|c|c|}
\hline Key Sustainability Criteria & Considerations for the program \\
\hline Strategic fit & $\begin{array}{l}\text { - Address a recognised gap in the market } \\
\text { - Solve a problem for the organisation } \\
\text { - Align to the strategic plan. }\end{array}$ \\
\hline Program identity & $\begin{array}{l}\text { - Identify the philosophy or identity of the program } \\
\text { - Clearly convey brand and communications } \\
\text { - Have a short, but succinct and clear pitch } \\
\text { - Ensure brand connects with participants and stakeholders. }\end{array}$ \\
\hline Co-design approach & $\begin{array}{l}\text { - Include input from potential participants } \\
\text { - Engage participants through the design and delivery process. }\end{array}$ \\
\hline The right person & $\begin{array}{l}\text { - Develop a clear position description for the program leader } \\
\text { - Integrate program leader into the organisation } \\
\text { - Provide an internal mentor for support and guidance } \\
\text { - Replace any leaver quickly and induct the new person. }\end{array}$ \\
\hline Plan to break even & $\begin{array}{l}\text { - Identify start-up costs } \\
\text { - Consider ongoing resources to support established program } \\
\text { - Consider sources of revenue outside government grants } \\
\text { - Establish the participant's preparedness to pay } \\
\text { - Plan how local delivery centres (e.g. clubs) can break even. }\end{array}$ \\
\hline $\begin{array}{l}\text { Local level growth, } \\
\text { implementation and support }\end{array}$ & $\begin{array}{l}\text { - Plan for and monitor quality assurance to maintain identity } \\
\text { - Train local level deliverers to be aware of program identity } \\
\text { - Provide tailored local level support } \\
\text { - Communicate case studies and successes as models } \\
\text { - Understand how and when to recruit more sites } \\
\text { - Plan to recruit and train a pool of good quality deliverers. }\end{array}$ \\
\hline Organisation buy-in & $\begin{array}{l}\text { - Obtain ongoing proactive, whole of organisation commitment } \\
\text { - Relate KPIs to the program in organisation's job descriptions. }\end{array}$ \\
\hline $\begin{array}{l}\text { Continuous improvement } \\
\text { as the program matures }\end{array}$ & $\begin{array}{l}\text { - Plan, do, review, improve } \\
\text { - Evaluate and re-confirm all aspects and commitment. }\end{array}$ \\
\hline
\end{tabular}




\section{CASE STUDIES}

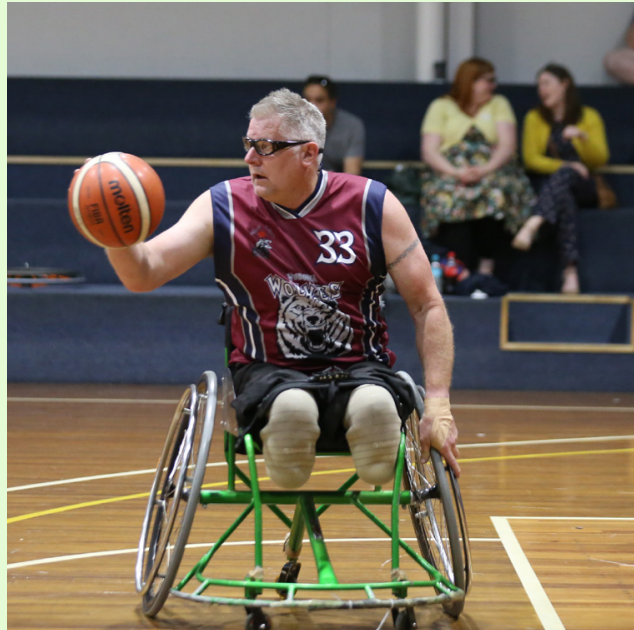

\section{Basketball Victoria}

The availability of wheelchairs was a key barrier to the sustainability and growth of Basketball Victoria's wheelchair basketball program. To overcome this, Basketball Victoria identified areas where there was most interest from local participants, clubs and other local partners (such as councils).
Program areas were also prioritised

according to location, with the aim of making programs available across the state.

In these areas, Basketball Victoria

initially helped clubs to share borrowed wheelchairs, and then assisted them to buy their own wheelchairs using channels such as government grants and corporate sponsorships or gifts.

Basketball Victoria provides strong support to a program when it is first established, then identifies local drivers and gradually reduces (rather than withdraws) support in order to focus on a new location. Support levels are well documented and communicated, so each club knows how much assistance to expect over time.

\section{This strategic approach supports growth} and is also an effective strategy to reduce program costs.

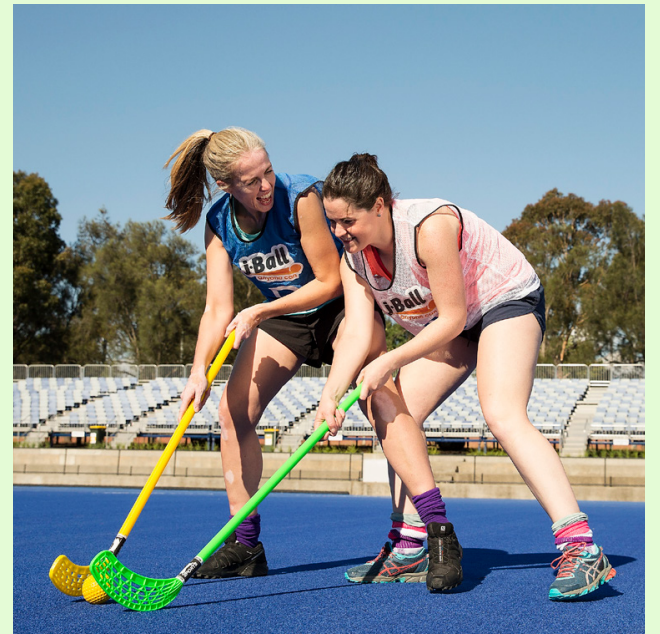

\section{Hockey Victoria}

As a step towards sustainability, Hockey Victoria has endorsed a recreational participation pathway in its recent strategic plan. This ensures that the Hockey Sixers and J-Ball programs will be resourced for growth, alongside the traditional competitive sport format. 


\section{Want to know more?}
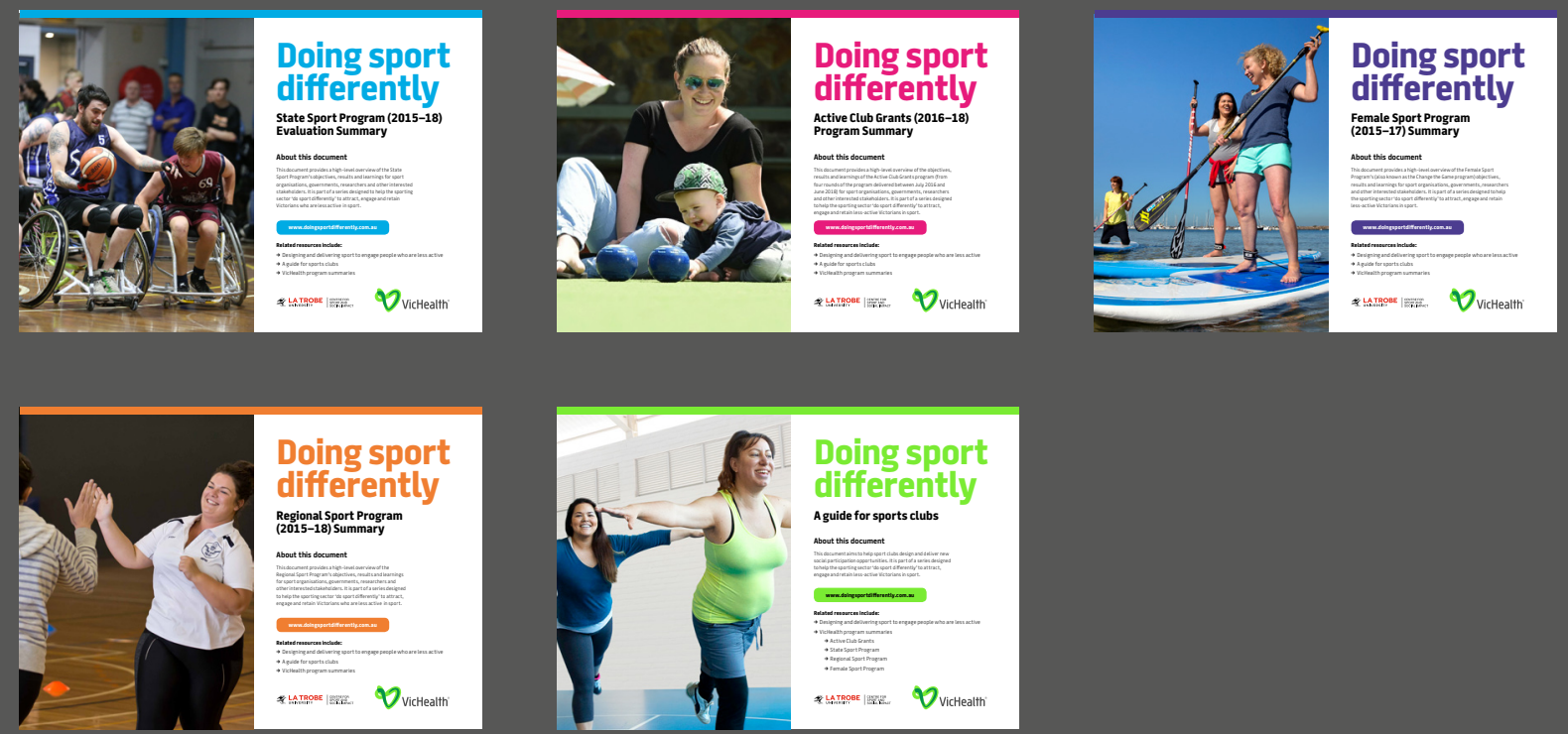

\section{Q VicHealth}

Victorian Health Promotion Foundation PO Box 154 Carlton South

Victoria 3053 Australia

$T+61396671333 F+61396671375$

vichealth@vichealth.vic.gov.au

vichealth.vic.gov.au

twitter.com/vichealth

facebook.com/vichealth

VicHealth acknowledges the support of the Victorian Government.

Australian Institute of Health and Welfare 2017, Impact of physical inactivity as a risk factor for chronic conditions: Australian Burden of Disease Study, Australian Institute of Health and Welfare, Canberra,

(www.aihw.gov.au/reports/burden-of-disease/impact-of-physical-inactivity-chronic-conditions).

Department of Health 2019, Australia's physical activity and sedentary behaviour guidelines, Department of Health, (www.health.gov.au/internet/main/publishing.nsf/Content/health-pubhlth-strateg-phys-act-guidelines).

Hajkowicz, SA, Cook, H, Wilhelmseder, L, Boughen, N 2013, The future of Australian sport: Megatrends shaping the sports sector over coming decades, CSIRO, Canberra, (https://doi.org/10.4225/08/584af378bffe1).

(c) VicHealth 2019

September 2019 P-PA-681

VIGTORIA 